\title{
The Impact Of Structured Exercise Programs On Metabolic Syndrome And Its Components: A Systematic Review
}

This article was published in the following Dove Press journal: Diabetes, Metabolic Syndrome and Obesity: Targets and Therapy

\author{
Megan S Joseph ${ }^{1, *}$ \\ Monica A Tincopa ${ }^{2} *$ \\ Patrick Walden' \\ Elizabeth Jackson $\mathbb{1 D}^{\prime}$ \\ Marisa L Conte $\mathbb{1}^{3}$ \\ Melvyn Rubenfire (iD) \\ 'Division of Cardiovascular Medicine, \\ ${ }^{2}$ Division of Gastroenterology and \\ Hepatology, ${ }^{3}$ Taubman Health Science \\ Library, University of Michigan Health \\ System, Ann Arbor, MI, USA \\ *These authors contributed equally to \\ this work
}

Background: The metabolic syndrome (MetS) is highly prevalent and associated with higher risk of diabetes and cardiovascular events. Exercise programs have been shown to improve components of MetS, but the optimal design of a structured exercise program for treatment of the MetS remains unclear.

Purpose: To assess the impact of different exercise programs on the MetS and its components.

Methods: MEDLINE via PubMed and Embase was searched. Randomized controlled trials of supervised exercise alone and in combination with nutrition programs compared with usual care in adults with the MetS were selected. Two authors independently reviewed articles to select eligible studies and performed data abstraction. Eight studies representing 1218 patients were included. The participants had a median age of 51 , median BMI of $29 \mathrm{~kg} / \mathrm{m}^{2}$, and were $55 \%$ male. Mean weight loss increased with program duration. For combination programs, the mean weight loss was $-2.6 \mathrm{~kg},-3.7 \mathrm{~kg}$, and $-6.5 \mathrm{~kg}$ for 3,6 , and 12 months, respectively. The components of the MetS most frequently statistically significantly improved were waist circumference (6/6 studies), blood pressure (4/6 studies), and high-density lipoprotein cholesterol (3/6 studies).

Limitations: Studies did not include long-term follow-up post program completion to evaluate persistence of benefit. It is unknown whether the same results would be found in an older, more obese population.

Conclusion: Supervised exercise programs yield significant resolution of components of the MetS, particularly in reducing waist circumference. Longer program duration and frequent interval sessions appear to have highest benefit and thus may help reduce cardiovascular risk and diabetes associated with the MetS.

Keywords: metabolic syndrome, exercise programs, obesity

\section{Introduction}

Obesity and metabolic syndrome (MetS) are highly prevalent worldwide. ${ }^{1}$ In the United States, metabolic syndrome is estimated to be present in approximately 30 $40 \%$ of the general population and is even more prevalent in older and minority populations. $^{2-4}$ The public health significance of the high prevalence of MetS is profound given that MetS is associated with a 2-fold risk of diabetes and increased risk of cardiovascular disease including hypertension, TIA/stroke, coronary heart disease, myocardial infarction, and the need for revascularization. ${ }^{1,5,6}$ While there are limitations to the commonly used definitions for MetS due to gender and ethnic
Correspondence: Melvyn Rubenfire Michigan Medicine Cardiovascular Medicine, Domino's Farms, Lobby A, 24 Frank Lloyd Wright Drive, Ann Arbor, MI 48105, USA

Tel + I $888287-4480$

$\mathrm{Fax}+1734998-9587$

Email mrubenfi@med.umich.edu 
differences for waist circumference and varying geneticbased susceptibility to cardiovascular disease, MetS criteria, particularly central or visceral obesity, remain meaningful risk factors for cardiovascular disease., ${ }^{7,8}$

Sedentary lifestyle is strongly associated with MetS and diabetes. $^{9-12}$ Prior studies have demonstrated an inverse relationship between the numbers of daily steps taken and MetS with a decreased odds of MetS for every 1000 steps/day increment. ${ }^{13}$ Owlasiuk et al noted that $61 \%$ of the adults with MetS had low or sedentary activity and $32 \%$ had negligible physical activity based on pedometer data. $^{14}$ Randomized controlled trials have consistently shown that increased physical activity can improve components of the MetS and thus represent a key treatment strategy. ${ }^{15-18}$ The precise value of exercise specifically for the treatment of MetS has been difficult to delineate given heterogeneity in study design and patient populations across studies, however. In particular, it remains unclear what value high versus moderate intensity incurs and whether the mode of exercise, i.e., aerobic versus strength versus interval training, variable impacts components of MetS. In addition, many lifestyle intervention programs include both dietary and physical activity components, and it is therefore difficult to isolate the benefit of exercise alone. In this setting, from a clinical practice standpoint, it has been challenging to provide evidence-based recommendations for exercise regimens targeted toward patients with MetS. The aim of this systematic review was to evaluate the impact of different types of structured exercise programs on the components of the MetS.

\section{Methods}

\section{Data Sources And Searches}

The systematic review was conducted following PRISMA guidelines. MEDLINE (via PubMed) and Embase were searched with the assistance of a medical research librarian. The following keywords were used for the search: "metabolic syndrome," "insulin resistance syndrome," "cardiometabolic syndrome," "exercise," "physical activity," "resistance training," "interval training," or "lifestyle intervention." Boolean operators and medical subject heading terms as well as other controlled vocabulary were used to enhance electronic searches. An example of specific search strategy details is shown in Supplementary Table 1.

All human subject studies published in full-text or abstract were eligible for inclusion. The search was limited to publications from 2000 to 2018 given that more contemporary studies included patient cohorts that are most reflective of current co-morbidities and patient characteristics as a result of the evolving obesity epidemic. Additional studies of interest were identified by hand searches of bibliographies. The initial search was performed in October 2017 and the search was last updated in January 2019. Due to the limited number of studies that met inclusion criteria for this systematic review and the significant heterogeneity in study design of the included papers, it was not statistically feasible to conduct a metaanalysis.

\section{Study Selection}

Two authors (M.S.J. and M.A.T) sequentially determined study eligibility. Studies were initially screened by the first author; decisions about study inclusion were made independently by both authors (M.S.J. and M.A.T). Differences in opinion regarding study inclusion were resolved through consensus. Studies were included if they: 1) included human studies with participants 18 years of age or older with MetS; 2) randomized controlled trials evaluating the effect of supervised structured exercise and combination lifestyle intervention programs compared with usual care; 3) evaluated impact on MetS criteria. The definitions for MetS were the NCEP ATP III, European, and Asian definitions. ${ }^{19-21}$ We excluded studies that were not available with an English translation.

\section{Data Extraction And Quality Assessment}

Two authors (M.S.J and M.A.T.) independently assessed the risk of study bias and study quality using the Downs and Black checklist. ${ }^{22}$ This system uses a 27-question scale to assess the quality of a study based on five domains: reporting, external validity, internal validity (bias), internal validity (confounding), and power.

\section{Data Synthesis And Analysis}

Data from eligible studies were abstracted by two authors (M.S.J. and M.A.T.). For all studies, we recorded study design, sample size, patient population characteristics, duration of program, and outcomes measured. Two authors qualitatively synthesized the results of the included studies. All authors had access to the study data and had reviewed and approved the final manuscript. We accepted the outcome definitions as stated by each study without independently validating or reviewing their data. 


\section{Results}

\section{Studies Included In The Systematic \\ Review}

After removal of duplicate entries, a total of 2385 unique articles were identified by our systematic literature search (Figure 1). On the basis of abstract review, 105 articles were selected for full-text review. Two study authors classified 8 articles as meeting the predefined criteria for analysis. Table 1 summarizes the design and outcomes of the included studies. These 8 studies included 1218 unique patients from 8 separate patient cohorts. The mean program duration was 22 weeks (range 12 weeks- 1 year). The average cohort size was 152 (range 21-464). In general, cohorts included 55\% males (range 0-100\%) with a median age of 51 years and BMI of $29 \mathrm{~kg} / \mathrm{m}^{2}$.

Of the included studies, 5 interventions involved aerobic exercise alone, 2 involved a combination of aerobic and resistance exercise, and 1 compared aerobic exercise with combination of aerobic and resistance exercise. Nutrition counseling was included in 4 studies. Design of the nutritional counseling varied and included individual, face-to-face meetings, group meetings, and nutrition diaries. Nutrition counseling included low-calorie, lowcarbohydrate and Mediterranean diets.

\section{Impact Of Programs On Metabolic Syndrome: Exercise + Nutritional Interventions}

Among programs with combination exercise and nutrition interventions, the median weight loss was $-3.7 \mathrm{~kg}$ (range -2.6 to $-6.5 \mathrm{~kg}$ ). Participants randomized to the usual care arm had a median weight loss of $-0.5 \mathrm{~kg}$. In terms of resolution of MetS and its components, the average change in waist circumference (WC), triglycerides (TG), highdensity lipoprotein cholesterol (HDL-C), blood pressure (systolic and diastolic), and fasting blood glucose (FBG) according to program design are shown in Tables 2 and 3.

\section{Impact Of Programs On Metabolic Syndrome: Exercise-Only Interventions}

Amongst programs with an exercise-only intervention, the median weight loss was $-1.8 \mathrm{~kg}$ (range -1.2 to $-3.6 \mathrm{~kg}$ ). Participants randomized to the control had a median weight change of $+0.5 \mathrm{~kg}$ (range -0.2 to $+0.8 \mathrm{~kg}$ ). The

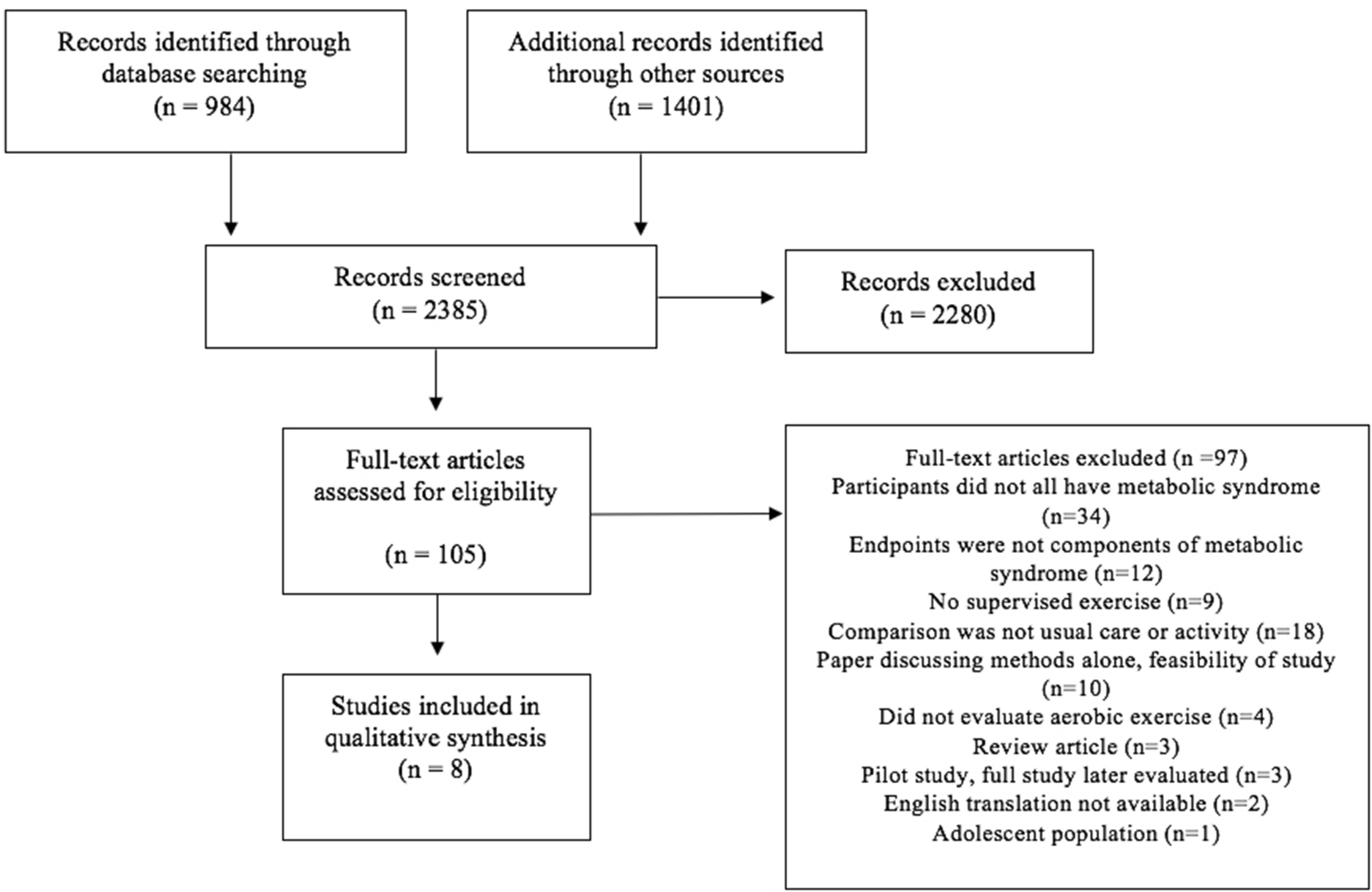

Figure I Literature search results and appraisal process. 
Table I Characteristics Of Studies

\begin{tabular}{|c|c|c|c|}
\hline Study & Population & $\begin{array}{l}\text { Program } \\
\text { Length }\end{array}$ & Intervention \\
\hline $\begin{array}{l}\text { Anderssen } 2007^{23} \\
\text { Norway }\end{array}$ & $\begin{array}{l}\text { I } 37 \text { adults with MetS } \\
100 \% \text { male } \\
\text { Mean age } 45 \\
\text { Mean BMI: } 29 \\
\% \text { with diabetes: NR } \\
\% \text { white: NR }\end{array}$ & 12 months & $\begin{array}{l}3 \text { intervention groups: } \\
\text { I) Dietary counseling alone } \\
\text { 2) Supervised exercise alone: Endurance-based, aerobic exercise, circuit } \\
\text { training, or jogging } 3 \text { times/week for } 60 \text { mins. } \\
\text { 3) Dietary counseling and supervised exercise }\end{array}$ \\
\hline $\begin{array}{l}\text { Pettman } 2009^{24} \\
\text { Australia }\end{array}$ & $\begin{array}{l}\text { I53 adults with MetS } \\
28 \% \text { male } \\
\text { Mean age: } 45 \\
\text { Mean BMI: } 37 \\
\% \text { with diabetes: NR } \\
\% \text { white: NR }\end{array}$ & 16 weeks & $\begin{array}{l}\text { "Shape up for Life" program consisting of: } \\
\text { - I two-hour session per week providing advice on diet and exercise. } \\
\text { - I one-hour supervised exercise session per week, consisting of aerobic } \\
\text { and resistance exercises. }\end{array}$ \\
\hline $\begin{array}{l}\text { Oh } 2010^{25} \\
\text { South Korea }\end{array}$ & $\begin{array}{l}52 \text { adults with MetS } \\
0 \% \text { male } \\
\text { Mean age: } 63 \\
\text { Mean BMI: } 26 \\
23 \% \text { with diabetes } \\
0 \% \text { white }\end{array}$ & 6 months & $\begin{array}{l}90 \text { min sessions. } 60 \text { sessions total ( } 3 \text { per week for } 3 \text { months, } 2 \text { per week for } \\
3 \text { months). } \\
\text { Program included food and exercise diaries, health education workshops, } \\
\text { and supervised exercise sessions (yoga and Tae-Bo). } \\
\text { Advised to follow a low-calorie, low-carbohydrate diet. }\end{array}$ \\
\hline $\begin{array}{l}\text { Liu } 2015^{17} \\
\text { Taiwan }\end{array}$ & $\begin{array}{l}464 \text { adults with MetSyn } \\
62 \% \text { male } \\
\text { Mean age: } 37 \\
\text { Mean BMI: } 28 \\
\% \text { with diabetes: NR } \\
0 \% \text { white }\end{array}$ & 6 months & $\begin{array}{l}\text { Low intensity lifestyle modification (LILM) program: } \\
\text { - } 16 \text { sessions over } 6 \text { months on exercise \& weight loss goals with I hr of } \\
\text { supervised aerobic exercise } \\
\text { - Food and exercise diaries }\end{array}$ \\
\hline $\begin{array}{l}\text { Tjonna } 2008^{26} \\
\text { Norway }\end{array}$ & $\begin{array}{l}32 \text { adults with MetS } \\
46 \% \text { male } \\
\text { Mean age: } 52 \\
\text { Mean BMl: } 30 \\
\% \text { with diabetes: NR } \\
\% \text { white: NR }\end{array}$ & 16 weeks & $\begin{array}{l}\text { Exercised } 3 \text { times/week. Randomized to: } \\
\text { I) Moderate continuous training (CME): exercising at } 70 \% \text { of highest } \\
\text { measured heart rate } 3 \text { times per week } \\
\text { 2) Aerobic interval training (AIT): exercising at } 90 \% \text { of highest measured } \\
\text { heart rate } 3 \text { times per week }\end{array}$ \\
\hline $\begin{array}{l}\text { Stensvold } 2010^{27} \\
\text { Norway }\end{array}$ & $\begin{array}{l}43 \text { adults with MetS } \\
60 \% \text { male } \\
\text { Mean age: } 50 \\
\text { Mean BMI: NR } \\
\% \text { with diabetes: NR } \\
\% \text { white: NR }\end{array}$ & 12 weeks & $\begin{array}{l}\text { Exercised } 3 \text { times/week: } \\
\text { 1) Aerobic interval training (AIT): walking or running at } 70 \% \text { peak predicted } \\
\text { heart rate } \\
\text { 2) Strength training (ST) } \\
\text { 3) Combination of AIT and ST (COM) }\end{array}$ \\
\hline $\begin{array}{l}\text { Damirchi } 2014^{38} \\
\text { Iran }\end{array}$ & $\begin{array}{l}21 \text { adults with MetS } \\
100 \% \text { male } \\
\text { Mean age: } 56 \\
\text { Mean BMl: } 27 \\
\% \text { with diabetes: NR } \\
\% \text { white: NR }\end{array}$ & 12 weeks & $\begin{array}{l}6 \text { weeks of aerobic training program ( } 3 \text { times/week) followed by } 6 \text { weeks of } \\
\text { detraining }\end{array}$ \\
\hline $\begin{array}{l}\text { Mora-Rodriguez } \\
2018^{28} \\
\text { Spain }\end{array}$ & $\begin{array}{l}163 \text { adults with MetS } \\
50 \% \text { male } \\
\text { Mean age: } 54 \\
\text { Mean BMI: } 32 \\
\% \text { with diabetes: NR } \\
\% \text { white: } 100 \%\end{array}$ & 16 weeks & Supervised aerobic interval training 3 times/week for 43 mins/session \\
\hline
\end{tabular}

Abbreviations: MetS, metabolic syndrome; WC, waist circumference; TG, triglycerides; sBP, systolic blood pressure; dBP, diastolic blood pressure; MAP, mean arterial pressure; FBG, fasting blood glucose; HDL-C, high-density lipoprotein; NR, not reported. 


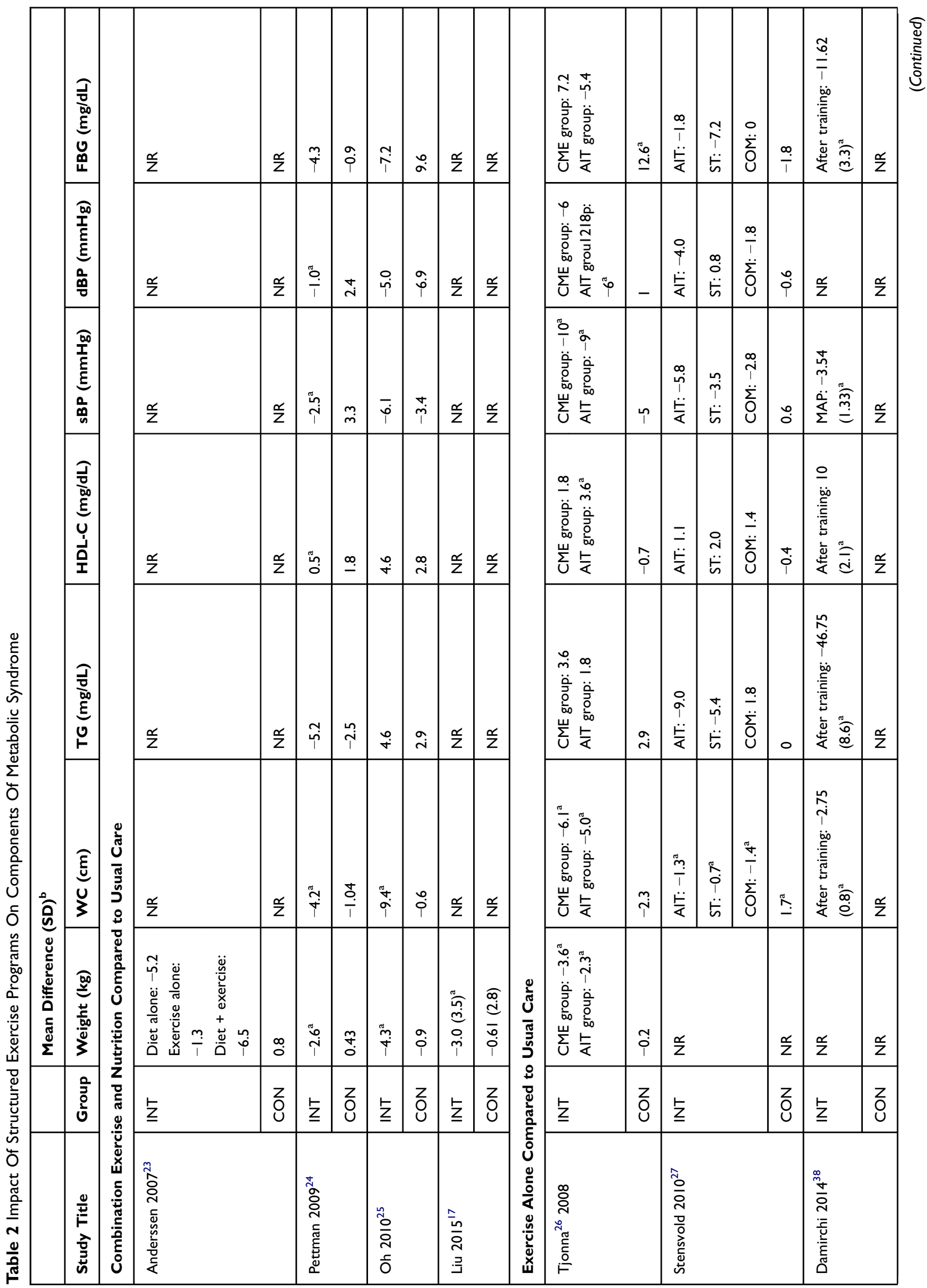


Table 3 Impact Of Structured Exercise Programs On Prevalence Of Metabolic Syndrome

\begin{tabular}{|c|c|c|}
\hline \multirow[t]{2}{*}{ Study Title } & \multicolumn{2}{|c|}{ Reduction In Prevalence Of MetS } \\
\hline & Intervention & Control \\
\hline \multicolumn{3}{|c|}{$\begin{array}{l}\text { Combination Exercise And Nutrition Compared To Usual } \\
\text { Care }\end{array}$} \\
\hline Anderssen $2007^{23}$ & $\begin{array}{l}\text { Diet alone: }-35 \%^{\mathrm{a}} \\
\text { Exercise alone: }-24 \% \\
\text { Diet }+ \text { exercise: }-67 \%^{\mathrm{a}}\end{array}$ & $-12 \%$ \\
\hline Pettman $2009^{24}$ & NR & NR \\
\hline Oh $2010^{25}$ & $-61 \%$ & $-30 \%$ \\
\hline Liu $2015^{17}$ & $-43 \%^{\mathrm{a}}$ & $-34 \%$ \\
\hline \multicolumn{3}{|c|}{ Exercise Alone Compared to Usual Care } \\
\hline Tjonna $2008^{26}$ & \multirow{2}{*}{$\begin{array}{l}\text { CME: }-38 \% \\
\text { AIT: }-45 \%^{\mathrm{a}} \\
\text { NR }\end{array}$} & $0 \%$ \\
\hline Stensvold $2010^{27}$ & & NR \\
\hline Damirchi $2014^{38}$ & NR & NR \\
\hline Mora-Rodriguez $2018^{28}$ & NR & NR \\
\hline
\end{tabular}

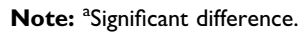

Abbreviations: MetS, metabolic syndrome; NR, not reported; CME, continuous moderate exercise; AIT, aerobic interval training.

average change in MetS, WC, TG, HDL, blood pressure, and FBG according to program design is shown in Tables 2 and 3.

\section{Quality Assessment And Risk Of Bias}

Studies were of moderate quality. The primary categories that received lower scores were internal validity-bias, internal validity-confounding and power (Supplementary Table 2).

\section{Discussion}

While obesity and a sedentary lifestyle have been associated with the development of the MetS, in clinical practice it has been challenging to provide evidence-based recommendations for physical activity as a primary therapy for the MetS and components. In particular, there has been conflicting evidence regarding the ideal type, frequency, and setting for exercise targeted toward resolution of components of MetS. Herein, we conducted a systematic review of the literature to identify randomized controlled trials of supervised exercise programs compared to usual care in order to better characterize the value of different exercise programs for the treatment of MetS. Our results reinforce the significant benefit of structured 
exercise for multiple components of MetS, particularly for reducing waist circumference, increasing HDL-C, and improving blood pressure. Moreover, these programs were effective across diverse patient cohorts despite relatively minimal time requirements and intensity of exercise.

As hypothesized, the randomized controlled trials that incorporated combination exercise and nutrition interventions seem to result in greater benefits when compared with exercise only interventions. ${ }^{17,23-25}$ The median weight loss in combined interventions was $-3.7 \mathrm{~kg}$ compared to $-1.8 \mathrm{~kg}$ in the exercise alone arms, with $61 \%$ of the participants having resolution of MetS compared to $38 \%$. Our findings highlight the point that nutritional changes are critical for weight loss. Salas-Salvado et al randomized a similar population of adults with MetS to a 12-month combination lifestyle intervention program, which involved following a Mediterranean diet, promoting physical activity, and behavioral support, or usual care. Although the intervention did not involve supervised aerobic exercise, the participants in the intervention group had an average weight loss of $-3.2 \mathrm{~kg}$ compared to $-0.7 \mathrm{~kg}$ in the control group $(\mathrm{p}<0.001)$. Participants in the intervention group also showed significant improvements in waist circumference $(-3.1 \mathrm{vs}-0.7 \mathrm{~cm}, \mathrm{p}<0.001)$, fasting blood glucose $(p=0.002)$ triglycerides $(p=0.002)$, and HDL-C $(\mathrm{p}<0.001){ }^{40}$

Our results also highlight the fact that exercise has significant metabolic benefits even in the absence of significant weight loss. ${ }^{23}$ This was demonstrated in a study by Malin et al in which individuals with the MetS participated in $300 \mathrm{mins} /$ week of exercise and were randomized to a high- versus low-glycemic diet. Interestingly, both groups showed similar improvements in waist circumference, blood pressure, triglycerides, and fasting glucose. ${ }^{39}$ In the 6 studies where data for each component of the MetS was reported, the components that were the most frequently improved were WC (6/6 studies), BP (4/6 studies), and HDL-C (3/6 studies). ${ }^{17,24-28}$ Interestingly, triglycerides appeared to be less responsive to exercise-based interventions possibly because triglyceride reduction is typically mild without weight loss.

In terms of mode of exercise that provides the highest yield for MetS, Tjonna et al compared moderate continuous training (CME) with aerobic interval training (AIT) and found some benefit to AIT, specifically a significantly greater reduction in fasting glucose $(-5.4 \mathrm{vs}+12.6 \mathrm{mg} / \mathrm{dL})$ and MetS prevalence $(-45 \%$ vs $0 \%)$. However, this finding requires further validation in larger cohorts. ${ }^{15,26}$ The added value of high- vs moderate-intensity exercise remains unclear. $^{41,29}$ In general, more frequent exercise appears to be more effective and is in line with general recommendations for exercise by the United States Preventive Task Force for 150 mins/week for adults. ${ }^{30}$ This is supported by data from a study by Kemmler et al where women with MetS were randomized to an exercise intervention (four 60-min sessions per week, combination of aerobic and strength training) or a wellness intervention (one 60-min session per week, low-intensity physical activity such as walking). After 12 months, the exercise group showed significant improvement in waist circumference, sBP, $\mathrm{dBP}$, triglycerides, and HDL-C. ${ }^{15}$ While strength training is often recommended in addition to aerobic training, the one study to evaluate this in the setting of a randomized clinical trial was unable to show significant additional benefit for the treatment of MetS. ${ }^{27}$ The duration of the program was the other key variable associated with degree of benefit for MetS. In general, a longer program duration was associated with greater weight loss. For the combination programs, the mean weight loss was $-2.6 \mathrm{~kg},-3.7 \mathrm{~kg}$, and $-6.5 \mathrm{~kg}$ for 3,6 , and 12 month programs, respectively.

Identifying cost-effective, scalable, and sustainable mechanisms to promote physical activity among persons with MetS is a key area of need. There is a strong foundation of literature that highlights the potential efficacy of telephone- and online-based follow-up that overcomes many of the logistical challenges of in-person visits. ${ }^{31-35}$ Fappa et al provided 87 adults with MetS with verbal instructions to follow a calorie-restricted, Mediterranean diet and increased physical activity. Participants were then randomized to a telephone intervention, which involved seven 20-min dietary counseling calls, face-to-face intervention, which involved seven one-on-one 1-hr dietary counseling sessions, or usual care. Interestingly, after 6 months, both intervention groups showed similar improvements in the prevalence of the MetS, WC, TG, and sBP and dBP. The face-to-face intervention only provided additional benefit for FBG. ${ }^{32}$ Similarly, a study by Christian et al randomized 279 adults to an online program that helped set personalized goals for weight loss, nutrition, and physical activity and addressed barriers to lifestyle changes or usual care. After 12 months, the intervention group showed significant improvements in weight and WC, demonstrating that significant improvements still can be gained if the infrastructure for frequent face-to-face visits is not available. ${ }^{33}$ The Diabetes Prevention Program (DPP) randomized patients at risk for diabetes to placebo, 
metformin, or a lifestyle intervention program, which recommended a goal of $7 \%$ weight loss and least 150 mins of physical activity per week. After 2.8 years, the lifestyle intervention program was associated with 58\% reduction in the incidence of diabetes when compared with placebo. ${ }^{36}$ After the DPP ended, participants were offered the option to continue in a maintenance phase of the program, which involved lifestyle sessions every 3 months and 4 group sessions per year. Ten years after DPP started, the incidence of diabetes was reduced by $34 \%$ in the lifestyle intervention group when compared with placebo. ${ }^{37}$ While all the patients in this study did not have metabolic syndrome, the participants had similar cardiovascular risk factors with an average BMI of 34.0, waist circumference of $105.1 \mathrm{~cm}$, and hemoglobin A1c of $5.91 \%$. This demonstrates that lifestyle intervention programs can provide long-term reduction in cardiovascular disease risk factors, even in high-risk populations.

This review does have limitations to note. First, the studies discussed did not have a component of long-term follow-up and so it is unknown whether participants maintain the metabolic benefits achieved with the intervention over time. Second, the median age of participants was 51 and median BMI was $29 \mathrm{~kg} / \mathrm{m}^{2}$ so it is unknown whether the same results would be found in an older, and/or more obese population. Lastly, the total number of studies eligible for the review was small, limiting the ability to compare in detail the impact of different designs of exercise interventions for MetS (interval, intensity, duration). This highlights an important unmet need in literature and outlines future studies that would add to our understanding of how best to guide therapy for patients with MetS.

In conclusion, in adults with MetS, structured exercise programs compared to usual care result in a modest but significant improvement in components of MetS, particularly waist circumference, HDL-C, and blood pressure, as well as an overall reduction in the prevalence of MetS. Combination exercise and nutrition interventions, longer program duration, and more frequent exercise sessions were associated with the greatest benefit. There is a strong foundation of data supporting that follow-up via phone or eHealth to facilitate and promote exercise is a low-cost and sustainable approach to implement physical activity as a primary therapy for MetS. More detailed assessments of different exercise programs over longer durations and with long-term follow-up are required to better delineate distinct benefits of different exercise programs for MetS.

\section{Acknowledgments}

The abstract of this paper was presented at the American College of Cardiology Conference as a poster presentation with interim findings. The poster's abstract was published in "Poster Abstracts" in the Journal of the American College of cardiology - http://www.onlinejacc.org/con tent/73/9 Supplement 1/1871.

\section{Disclosure}

Monica Tincopa (formerly Konerman) receives funding support from the AASLD Clinical Translational and Outcomes Research Award. Elizabeth A Jackson reports personal fees from NIH and Amgen Research paid to UAB (home institution); personal fees paid directly to EAJ from NIH study section; American Heart Assoc. Editorial board, Up-To-Date consultant, McKesson consultant, Deblase, and Brown, Everly, LLP, expert witness. EAJ reports personal consultant fees from American College of Cardiology. The authors report no other conflicts of interest in this work.

\section{References}

1. Engin A. The definition and prevalence of obesity and metabolic syndrome. Adv Exp Med Biol. 2017;960:1-17. doi:10.1007/978-3319-48382-5_1

2. Ford ES, Giles WH, Dietz WH. Prevalence of the metabolic syndrome among US adults: findings from the third National Health and Nutrition Examination Survey. JAMA. 2002;287(3):356-359. doi:10.1001/jama.287.3.356

3. Grundy SM, Brewer HB Jr., Cleeman JI, et al. Definition of metabolic syndrome: report of the National Heart, Lung, and Blood Institute/ American Heart Association conference on scientific issues related to definition. Arterioscler Thromb Vasc Biol. 2004;24(2):e13-e18. doi:10.1161/01.ATV.0000137975.14996.df

4. Mozumdar A, Liguori G. Persistent increase of prevalence of metabolic syndrome among U.S. adults: NHANES III to NHANES 19992006. Diabetes Care. 2011;34(1):216-219. doi:10.2337/dc10-0879

5. Malik S, Wong ND, Franklin SS, et al. Impact of the metabolic syndrome on mortality from coronary heart disease, cardiovascular disease, and all causes in United States adults. Circulation. 2004;110 (10):1245-1250. doi:10.1161/01.CIR.0000140677.20606.0E

6. Wang YC, McPherson K, Marsh T, Gortmaker SL, Brown M. Health and economic burden of the projected obesity trends in the USA and the UK. Lancet (London, England). 2011;378(9793):815-825. doi:10.1016/S0140-6736(11)60814-3

7. Zafar U, Khaliq S, Ahmad HU, Manzoor S, Lone KP. Metabolic syndrome: an update on diagnostic criteria, pathogenesis, and genetic links. Hormones (Athens). 2018;17(3):299-313. doi:10.1007/s42000018-0051-3

8. Goh LG, Dhaliwal SS, Welborn TA, Lee AH, Della PR. Anthropometric measurements of general and central obesity and the prediction of cardiovascular disease risk in women: a cross-sectional study. BMJ Open. 2014;4 (2):e004138. doi:10.1136/bmjopen-2013-004138

9. Edwardson CL, Gorely T, Davies MJ, et al. Association of sedentary behaviour with metabolic syndrome: a meta-analysis. PLoS One. 2012;7(4):e34916. doi:10.1371/journal.pone.0034916 
10. van der Berg JD, Stehouwer CD, Bosma H, et al. Associations of total amount and patterns of sedentary behaviour with type 2 diabetes and the metabolic syndrome: the maastricht study. Diabetologia 2016;59(4):709-718. doi:10.1007/s00125-015-3861-8

11. Bankoski A, Harris TB, McClain JJ, et al. Sedentary activity associated with metabolic syndrome independent of physical activity. Diabetes Care. 2011;34(2):497-503. doi:10.2337/dc10-0987

12. Honda T, Chen S, Yonemoto K, et al. Sedentary bout durations and metabolic syndrome among working adults: a prospective cohort study. BMC Public Health. 2016;16:888. doi:10.1186/s12889-0163570-3

13. Newton RL, Han H, Johnson WD, et al. Steps/day and metabolic syndrome in African American adults: the Jackson Heart Study. Prev Med. 2013;57(6):855-859. doi:10.1016/j.ypmed.2013.09.018

14. Owlasiuk A, Chlabicz S, Gryko A, Litwiejko A, Małyszko J, Bielska D. Pedometer assessed physical activity of people with metabolic syndrome in Poland. Ann Agric Environ Med. 2014;21(2):353-358. doi:10.5604/1232-1966.1108604

15. Kemmler W, Von Stengel S, Engelke K, Kalender WA. Exercise decreases the risk of metabolic syndrome in elderly females. Med Sci Sports Exerc. 2009;41(2):297-305. doi:10.1249/MSS.0b013e31818844b7

16. Verrusio W, Andreozzi P, Renzi A, et al. Efficacy and safety of spinning exercise in middle-aged and older adults with metabolic syndrome: randomized control trial. Ann Ist Super Sanita. 2016;52(2):295-300. doi:10.4415/ANN_16_02_24

17. Liu YL, Lu CW, Shi $\bar{L}$, Liou YM, Lee LT, Huang KC. Low intensive lifestyle modification in young adults with metabolic syndrome a community-based interventional study in Taiwan. Medicine (Baltimore). 2015;94(22):e916. doi:10.1097/ MD.0000000000000874

18. Tran VD, James AP, Lee AH, Jancey J, Howat PA, Thi Phuong Mai L. Effectiveness of a community-based physical activity and nutrition behavior intervention on features of the metabolic syndrome: a cluster-randomized controlled trial. Metab Syndr Relat Disord. 2017;15 (2):63-71. doi:10.1089/met.2016.0113

19. Alberti KG, Eckel RH, Grundy SM, et al. Harmonizing the metabolic syndrome: a joint interim statement of the International Diabetes Federation Task Force on Epidemiology and Prevention; National Heart, Lung, and Blood Institute; American Heart Association; World Heart Federation; International Atherosclerosis Society; and International Association for the Study of Obesity. Circulation. 2009;120(16):1640 1645. doi:10.1161/CIRCULATIONAHA.109.192644

20. Esteghamati A, Abbasi M, Rashidi A, et al. Optimal waist circumference cut-offs for the diagnosis of metabolic syndrome in Iranian adults: results of the third national survey of risk factors of noncommunicable diseases (SuRFNCD-2007). Diabet Med. 2009;26 (7):745-746. doi:10.1111/j.1464-5491.2009.02756.x

21. Expert Panel on Detection Ea, and Treatment of High Blood Cholesterol in Adults. Executive summary of the third report of the National Cholesterol Education Program (NCEP) expert panel on detection, evaluation, and treatment of high blood cholesterol in adults (adult treatment Panel III). Jama. 2001;285(19):2486-2497. doi:10.1001/jama.285.19.2486

22. Downs SH, Black N. The feasibility of creating a checklist for the assessment of the methodological quality both of randomised and non-randomised studies of health care interventions. $J$ Epidemiol Community Health. 1998;52(6):377-384. doi:10.1136/ jech.52.6.377

23. Anderssen SA, Carroll S, Urdal P, Holme I. Combined diet and exercise intervention reverses the metabolic syndrome in middleaged males: results from the Oslo Diet and Exercise Study. Scand $J$ Med Sci Sports. 2007;17(6):687-695. doi:10.1111/j.16000838.2006.00631.x
24. Pettman TL, Buckley JD, Misan GM, Coates AM, Howe PR. Health benefits of a 4-month group-based diet and lifestyle modification program for individuals with metabolic syndrome. Obes Res Clin Pract. 2009;3(4):221-235. doi:10.1016/j.orcp.2009.06.002

25. Oh EG, Bang SY, Hyun SS, et al. Effects of a 6-month lifestyle modification intervention on the cardiometabolic risk factors and health-related qualities of life in women with metabolic syndrome. Metabolism. 2010;59 (7):1035-1043. doi:10.1016/j.metabol.2009.10.027

26. Tjonna AE, Lee SJ, Rognmo O, et al. Aerobic interval training versus continuous moderate exercise as a treatment for the metabolic syndrome: a pilot study. Circulation. 2008;118(4):346-354. doi:10.1161/ CIRCULATIONAHA.108.772822

27. Stensvold D, Tjonna AE, Skaug EA, et al. Strength training versus aerobic interval training to modify risk factors of metabolic syndrome. J Appl Physiol (1985). 2010;108(4):804-810. doi:10.1152/ japplphysiol.00996.2009

28. Mora-Rodriguez R, Ortega JF, Morales-Palomo F, Ramirez-Jimenez M. Weight loss but not gains in cardiorespiratory fitness after exercise-training predicts improved health risk factors in metabolic syndrome. Nutr Metab Cardiovasc Dis. 2018;28(12):1267-1274. doi:10. 1016/j.numecd.2018.08.004

29. Wewege M, van Den Berg R, Ward RE, Keech A. The effects of high-intensity interval training vs. moderate-intensity continuous training on body composition in overweight and obese adults: a systematic review and meta-analysis. Obes Rev. 2017;18(6):635646. doi:10.1111/obr. 12532

30. Patnode CD, Evans CV, Senger CA, Redmond N, Lin JS. Behavioral Counseling to Promote a Healthful Diet and Physical Activity for Cardiovascular Disease Prevention in Adults without Known Cardiovascular Disease Risk Factors: Updated Systematic Review for the U.S. Preventive Services Task Force. Rockville (MD); 2017.

31. Oh B, Cho B, Han MK, et al. The effectiveness of mobile phone-based care for weight control in metabolic syndrome patients: randomized controlled trial. JMIR mHealth uHealth. 2015;3(3):e83. doi:10.2196/mhealth.3949

32. Fappa E, Yannakoulia M, Ioannidou M, Skoumas Y, Pitsavos C, Stefanadis C. Telephone counseling intervention improves dietary habits and metabolic parameters of patients with the metabolic syndrome: a randomized controlled trial. Rev Diabet Stud. 2012;9(1):36-45. doi:10.1900/RDS.2012.9.36

33. Christian JG, Byers TE, Christian KK, et al. A computer support program that helps clinicians provide patients with metabolic syndrome tailored counseling to promote weight loss. J Am Diet Assoc. 2011;111(1):75-83. doi:10.1016/j.jada.2010.10.006

34. Jahangiry L, Montazeri A, Najafi M, Yaseri M, Farhangi MA. An interactive web-based intervention on nutritional status, physical activity and health-related quality of life in patient with metabolic syndrome: a randomized-controlled trial (The Red Ruby Study). Nutr Diabetes. 2017;7(1):e240. doi:10.1038/nutd.2016.35

35. Kim CJ, Schlenk EA, Kang SW, Park JB. Effects of an internet-based lifestyle intervention on cardio-metabolic risks and stress in Korean workers with metabolic syndrome: a controlled trial. Patient Educ Couns. 2015;98(1):111-119. doi:10.1016/j.pec.2014.10.013

36. Knowler WC, Barrett-Connor E, Fowler SE, et al. Reduction in the incidence of type 2 diabetes with lifestyle intervention or metformin. $N$ Engl J Med. 2002;346(6):393-403. doi:10.1056/NEJMoa012512

37. Knowler WC, Fowler SE, et al; Diabetes Prevention Program Research G. 10-year follow-up of diabetes incidence and weight loss in the Diabetes Prevention Program Outcomes Study. Lancet (London, England). 2009;374(9702):1677-1686. doi:10.1016/S0140-6736(09)61457-4

38. Damirchi A, Tehrani BS, Alamdari KA, Babaei P. Influence of aerobic training and detraining on serum BDNF, insulin resistance, and metabolic risk factors in middle-aged men diagnosed with metabolic syndrome. Clin J Sport Med. 2014;24(6):513-518 
39. Malin SK, Niemi N, Solomon TP, et al. Exercise training with weight loss and either a high- or low-glycemic index diet reduces metabolic syndrome severity in older adults. Ann Nutr Metab. 2012;61(2):135141. doi:10.1159/000342084

40. Salas-Salvado J, Diaz-Lopez A, Ruiz-Canela M, et al. Effect of a lifestyle intervention program with energy-restricted mediterranean diet and exercise on weight loss and cardiovascular risk factors: oneyear results of the PREDIMED-plus trial. Diabetes Care. 2018. doi: $10.2337 / \mathrm{dc} 18-0836$
41. Fisher G, Brown AW, Bohan Brown MM, et al. High intensity intervalvs moderate intensity- training for improving cardiometabolic health in overweight or obese males: a randomized controlled trial. PLoS One. 2015;10(10):e0138853. doi:10.1371/journal.pone.0138853

\section{Publish your work in this journal}

Diabetes, Metabolic Syndrome and Obesity: Targets and Therapy is an international, peer-reviewed open-access journal committed to the rapid publication of the latest laboratory and clinical findings in the fields of diabetes, metabolic syndrome and obesity research. Original research, review, case reports, hypothesis formation, expert opinion and commentaries are all considered for publication. The manuscript management system is completely online and includes a very quick and fair peer-review system, which is all easy to use. Visit http://www.dovepress.com/testimonials.php to read real quotes from published authors. 